\title{
Prospective clinico mycological study of superficial mycosis in coastal Andhra Pradesh
}

\author{
K. Ramesh ${ }^{1}$, MSN Murthy ${ }^{2, *}$, M. Manjan Annapurna ${ }^{3}$ \\ ${ }^{\mathbf{1}}$ Assistant Professor, ${ }^{\mathbf{2}}$ Associate Professor, ${ }^{\mathbf{3}}$ Post Graduate, Dept. of DVL, Konaseema Institute of Medical Sciences Amalapuram \\ Andhra Pradesh, India \\ *Corresponding Author: \\ Email: murthy_msn@gmail.com
}

\begin{abstract}
Introduction: Indian continent has remarkable topographical variation between tropical and subtropical regions of the world. For this reasons, superficial mycoses is common in our country. There are other predisposing factors, like socioeconomic condition, overcrowded, poor hygiene, and contact with animal, and in the absence of proper medical care skin mycoses spread epidemically. In addition to its epidemic nature, the spectrum of dermatophytosis is also not static. Konaseema region is costal part of Andhra Pradesh, and no such study has been conducted in this region, so present study has been designed to study the clinical pattern of superficial mycoses among the patients who are attending outpatient department of Dermatology, venereology and leprosy and also to study the variations of species causing different morphological forms of superficial mycoses.

Materials and Methods: Present study is a randomized cross sectional prospective study conducted in the dermatology, venereology and leprology department Konaseema institute of medical sciences Amalapuram from February 2016 to May 2018. The study population include 1200 patients diagnosed clinically having superficial mycoses randomly selected for this study based on exclusion and inclusion criteria.

Result: Out of 1200 patients $786(65.5 \%)$ were diagnosed as dermatophytosis $146(12.1 \%)$ patients were diagnosed as pityriasis versicolor, $224(18.666 \%)$ patients were diagnosed to be candidiasis and 44 (3.66\%) patients were having tinea nigra. Out of 786 dermatophytes, $320(49.10 \%)$ were clinically diagnosed as T. Cruris, $240(30.53 \%)$ patients were clinically diagnosed as tinea. corporis, 104 patients (13.23\%) were diagnosed as tinea Unguium, tinea mannum patients were 44 in number $(5.59 \%)$, T capitis patients were 26, $(3.3 \%) .20$ patients that is $2.5 \%$ were diagnosed to be tinea. Barbae and $12(1.5 \%)$ patients were diagnosed to be tinea. Faciei $2.5 \%$ patients were diagnosed to have tinea pedis.

Discussion and Conclusion: We have found that it is common in $2^{\text {nd }}$ and $3^{\text {rd }}$ decade of life with male predominance. It is common in middle income group. Dermatophytosis is most common clinical types and in that tinea crusis is most common clinical presentation, followed by candidiasis tinea. Rubrum was the most common species isolated. Among candidiasis balanoposthitis was most common presentation.
\end{abstract}

Keywords: Superficial mycosis, Clinico mycology, Dermatophytosis.

\section{Introduction}

Fungus infections are extremely common infection but some of them are serious and even fatal. This is broadly divided in two types, superficial infection and systemic mycosis, another type of mycosis is opportunistic infection. Superficial mycoses are of two types' Surface infections and cutaneous infection. In surface infection fungi infect dead layer of the skin without inflammatory response the only concern is cosmetic, for example, pityriasis Versicolor, tinea nigra and tinea piedra. In cutaneous infection cornified layer of skin is effected with a variety of inflammatory and immunological responses, due to presence of fungus and its metabolite. Dermatophytes are important cutaneous infection which is classified into trichophyton, epidermophyton and microsporum ${ }^{1}$ Superficial fungal infection is common in general population, and it has been observed by the work of Aggarwal A et al and Vander Straten et al, that skin mycosis affect more than $20 \%$ of the global population, which has made it one of the most frequent form of infection. ${ }^{2,3}$ It has also been observed that superficial mycosis has worldwide in distribution, the epidemiology and causative species of dermatophytes also differs from one geographical area to another. ${ }^{4-6}$ Dermatophytes require surface temp $25-28^{\circ} \mathrm{C}$ and infection in human require hot and humid environment. Indian continent has remarkable topographical variation between tropical and subtropical regions of the world. For this reasons, superficial mycoses is common in our country. There are other predisposing factors, like socioeconomic condition, overcrowding, poor hygiene, and contact with animal, and in the absence of proper medical care skin mycoses spread epidemically. In addition to its epidemic nature, the spectrum of dermatophytosis is also not static. ${ }^{7-9}$

Studies have been conducted on superficial mycoses in various part of India and has concluded the variation in epidemiology and septum of dermatophytes in different reasons. ${ }^{5-7,9}$ Konaseema region is costal part of Andra Pradesh, and no such study has been conducted in this region, so present study has been designed to study the clinical pattern of superficial mycoses among the patients who are attending outpatient department of Dermatology, venereology and leprosy and also to study the variations of species causing different morphological forms of superficial mycoses. 


\section{Materials and Methods}

Present study is a randomized cross sectional prospective study conducted in the dermatology, venereology and leprology department Konaseema institute of medical science Amalapuram from February 2016 to May 2018.

Study Population: The study population include 1200 patients diagnosed clinically having superficial mycoses randomly selected for this study based on exclusion and inclusion criteria.

\section{Inclusion Criteria}

1. Both sex

2. All age

3. Clinically diagnosed superficial mycosis

\section{Exclusion Criteria}

1. Pt with DM, HIV, Tuberculosis, leprosy and on any medication like steroid or immunosuppressive agent.

2. History of treatment with topical or oral anti-fungal drugs within four month.

Ethics: Present study is approved by institutional ethics committee. A written informed consent was taken from all patients before enrolment for study and from minor age group patients consent was taken from parent.

Method: A detail history was taken from all patients that include, age, sex, and occupation, duration of disease, socioeconomic status and history of treatment. A thorough clinical examination was done and relevant systemic examination was also done and finding was recorded. The skin scraping was collected from the active edge of the lesion, nail clipping and subungal debris collected for tinea unguium patient. Infected and lustreless hair was collected for tinea capitis, for candidiasis, sample was collected form whitish deposits or pustular lesion. Investigation was done by directly microscopy, scrapping was placed on a clean sterilized glass slide and drops of $10 \% \mathrm{KOH}$ was poured and covered with cover slip with a gentle measure. For nail $20 \% \mathrm{KOH}$ was used the slides were examined for fungal hyphae, spores and for detection of type of hair infection (ectothrix or endothrix). Sabouraud's dextrose agar was used for culture with chloramphenicol, gentamycin, and cholorhexidine. Proper precaution was taken to prevent contamination. The scraping was inoculated onto the agar slant and was incubated at $25^{\circ} \mathrm{c}$ and $37^{\circ} \mathrm{c}$. If there is no growth at the end of 4 weeks the culture was discarded. Gross morphology and microscopy was used for identification of fungal colonies. Microscopic examination was done by preparing teased mounts or slide cultures from the isolates with a drop of lacto phenol cotton blue stain. For Trichophyton species, urease and hair perforation test was done. Germ tube test was done to identify candida species. Wood lamp examination was done in dark room with no windows. The light source was 4-6 inches away from skin.

\section{Result}

During the period of two year and three months a total of 1200 clinically diagnosed new cases of superficial mycoses attending the outpatient department of Dermatology, venereology and Leprology, Konaseema institute of medical science Amalapuram.

Table 1: Demographic profile of patients

\begin{tabular}{|l|c|c|c|}
\hline \multicolumn{2}{|c|}{ Variables } & Number & $\%$ \\
\hline \multirow{3}{*}{ Age(yrs) } & $0-15$ & 186 & $15.5 \%$ \\
\cline { 2 - 4 } & $15-45$ & 697 & $57.25 \%$ \\
\cline { 2 - 4 } & $45-60$ & 221 & $18.41 \%$ \\
\cline { 2 - 4 } & $>60$ & 96 & $8 \%$ \\
\hline \multirow{2}{*}{ Sex } & $\mathrm{M}$ & 946 & $78.83 \%$ \\
\cline { 2 - 4 } & $\mathrm{F}$ & 264 & $21.17 \%$ \\
\hline \multirow{2}{*}{$\begin{array}{l}\text { Socioeconomic } \\
\text { statics }\end{array}$} & Low & 230 & $19.16 \%$ \\
\cline { 2 - 4 } & Middle & 866 & $72.16 \%$ \\
\cline { 2 - 4 } & high & 104 & $8.66 \%$ \\
\hline
\end{tabular}

Out of 1200 patients diagnosed to be superficial mycosis $15.5 \%$ were below 15 yrs of age. 697 patients $(57.25 \%)$ were between 15 to $45 \mathrm{yrs}, 221$ patients $(18.41 \%)$ were between $45-60 \mathrm{yrs}$ and $8 \%$ patients were above $60 \mathrm{yrs}$ of age. Out of all patients $78.83 \%$ were male and $21.17 \%$ were female. $19.16 \%$ patients were have low socioeconomic background. $72.15 \%$ were having middle socioeconomic back ground and rest were belong to upper socioeconomic group.

Table 2: Clinical type of superficial mycoses $(n=1200)$

\begin{tabular}{|l|c|c|}
\hline \multicolumn{1}{|c|}{ Types } & $\begin{array}{c}\text { Number of } \\
\text { patients }\end{array}$ & Percent age \\
\hline Dermatophytosis. & 786 & $65.5 \%$ \\
\hline $\begin{array}{l}\text { Pityriasis } \\
\text { Versicolor }\end{array}$ & 126 & $10.5 \%$ \\
\hline Candidiasis & 224 & $18.66 \%$ \\
\hline Tinea Nigra & 64 & $5.33 \%$ \\
\hline Total & 1200 & $(100 \%)$ \\
\hline
\end{tabular}

Table 3: Clinical types of dermatophytes and candidiasis

\begin{tabular}{|l|c|c|}
\hline \multicolumn{1}{|c|}{ Types } & Number & $\%$ \\
\hline Dermatophytes (n=786) \\
\hline Tinea. Cruris & 320 & $49.10 \%$ \\
\hline Tinea. Corporis & 240 & $30.53 \%$ \\
\hline Tinea.Unguium & 104 & $13.23 \%$ \\
\hline Tinea.Mannum & 44 & $5.59 \%$ \\
\hline Tinea. Capitis & 26 & $3.30 \%$ \\
\hline Tinea. Barbae & 20 & $2.5 \%$ \\
\hline Tinea.Faciei & 12 & $1.5 \%$ \\
\hline Tinea.Pedis & 20 & $2.5 \%$ \\
\hline Candidiasis $(n=224)$ & \multicolumn{2}{|l|}{} \\
\hline paronychia & 24 & $10.71 \%$ \\
\hline oral & 16 & $7.14 \%$ \\
\hline Intertrigo & 30 & $13.39 \%$ \\
\hline
\end{tabular}




\begin{tabular}{|l|c|c|}
\hline Balanoposthitis & 112 & $50.00 \%$ \\
\hline Vulvovaginitis & 36 & $16.071 \%$ \\
\hline Glossitis & 6 & $2.6 \%$ \\
\hline
\end{tabular}

Table 4: Comparison of $\mathrm{KOH}$ positivity with culture positivity in different clinical types of superficial mycoses

\begin{tabular}{|l|c|c|c|}
\hline \multicolumn{1}{|c|}{ Clinical types } & Number of patients & KOH smear positive & Culture positive \\
\hline Dermatophytosis & 786 & $336(42.74 \%)$ & $494(62.83 \%)$ \\
\hline Pityriasis Versicolor & 146 & 82 & 62 \\
\hline candidiasis & 224 & $106(47.32 \%)$ & $184(82.14 \%)$ \\
\hline Tinea nigra & 44 & 4 & 36 \\
\hline
\end{tabular}

Table 5: Frequency of species of mycological isolates $(n=776)$

\begin{tabular}{|c|c|c|}
\hline species & Number of isolates & Percentage (\%) \\
\hline \multicolumn{3}{|l|}{ Dermatophytes $=494(63.65 \%)$} \\
\hline Trichophyton Rubrum & 222 & 44.93 \\
\hline Trichophyton Mentagrophyte & 196 & 37.65 \\
\hline Trichophyton Tonsurans & 18 & 3.6 \\
\hline Trichophyton Violaceum & 46 & 9.3 \\
\hline Microsporum Audouinii & 10 & 2.02 \\
\hline Trichophyton Schoenlenii & 12 & 2.4 \\
\hline \multicolumn{3}{|c|}{ Non Dermatophytes yeast $(N=184)$} \\
\hline Malassezia species. & 72 & 39.13 \\
\hline Candida & 112 & 60.47 \\
\hline \multicolumn{3}{|c|}{ Non Dermatophytes Moulds $(n=98)(12.62 \%)$} \\
\hline Aspergillus Niger & 48 & 48.97 \\
\hline Aspergillus Flavus & 24 & 24.48 \\
\hline Aspergillus. Carrionii & 14 & 14.28 \\
\hline Exophiala. Jeanselmei & 8 & 8.1 \\
\hline Hortaea Werneckii & 4 & 4.2 \\
\hline
\end{tabular}

As per table 2 out of 1200 patients 786 were diagnosed as dermatophytosis that $65.5 \%$ of total patients 146 patients were diagnosed as pityriasis versicolor, which is $12.1 \%$. 224 patients were diagnosed to be Candidiasis that is $18.666 \%$. 44 patients were having tinea nigra that is $3.66 \%$

In present study as per table -3 out of 786 dermatophytes, $320(49.10 \%)$ were clinically diagnosed as tinea cruris, $240(30.53 \%)$ patients were clinically diagnosed as tinea corporis, 104 patients (13.23\%) were diagnosed as tinea unguium, tinea mannum patients were 44 in number $(5.59 \%)$, $\mathrm{t}$ capitis patients were $26,(3.3 \%)$. 20 patients that is $2.5 \%$ were diagnosed to be tinea barbae and $12(1.5 \%)$ patients were diagnosed to be tinea faciei. $2.5 \%$ patients were diagnosed to have tinea pedis.

Out of 224 candidiasis patients, $24(10.71 \%)$ having paronychia, $16(7.14 \%)$ having oral candidiasis, 30 patients presented with intertigo that $13.39 \% .112$ (50.00\%) were presented with balanoposthitis and 36 patients were having Vulvovaginitis that $16.07 \%$ and 6 patients presented with glositis.

In present study as per table- 4 we have found that culture positivity was higher in dermatophytosis and candidiasis in comparison to pityriasis versicolor than $\mathrm{KOH}$ moult.
In 772 culture positive cases dermatophytes were isolated in $63.65 \%$ of the patients, which is followed by yeast that is $23.71 \%$ and non dermatophytes moulds $(12.62 \%)$.

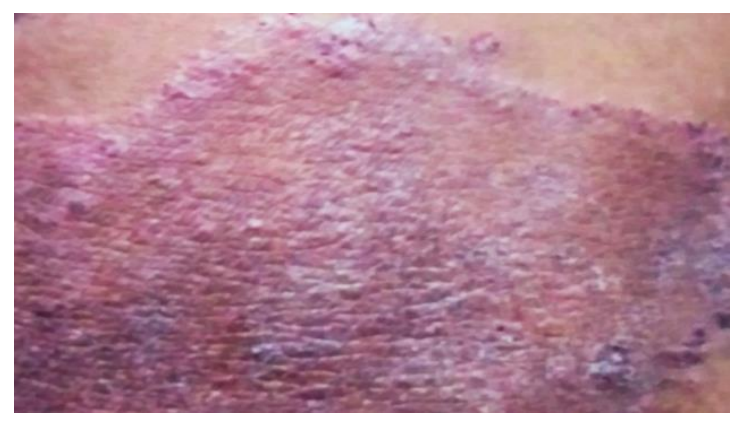

Fig. 1: Tinea corporis

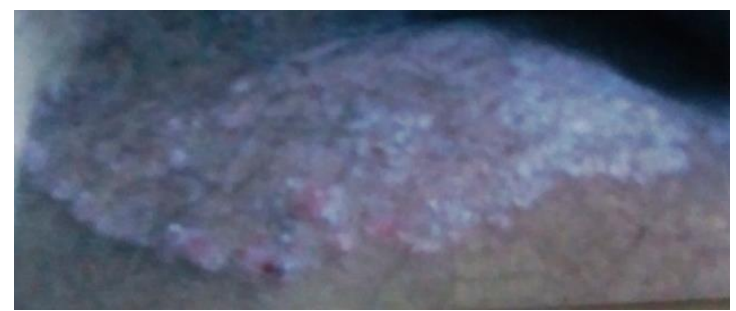

Fig. 2: Tinea cruris 


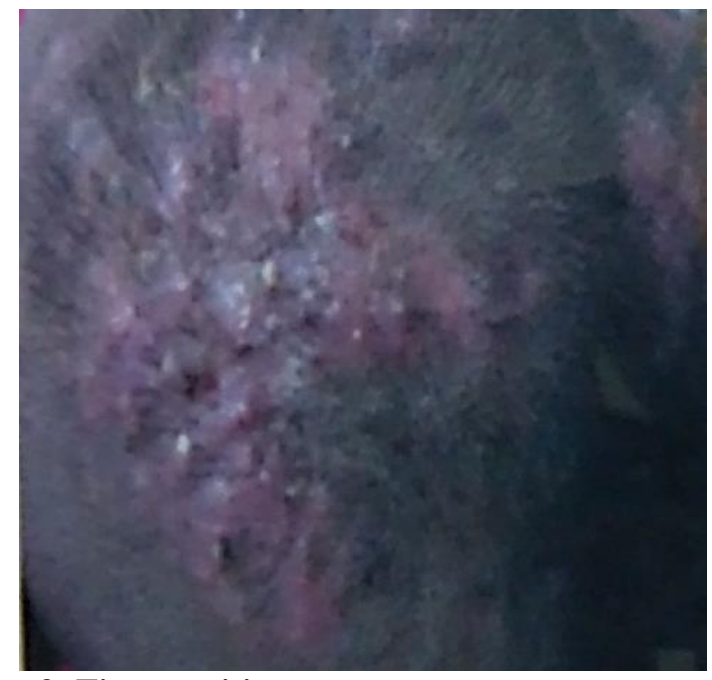

Fig. 3: Tinea capitis

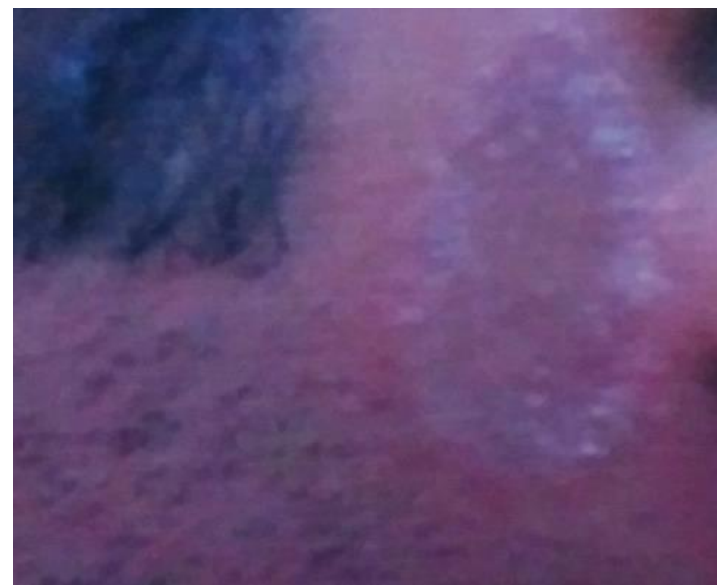

Fig. 4: Tinea faciei

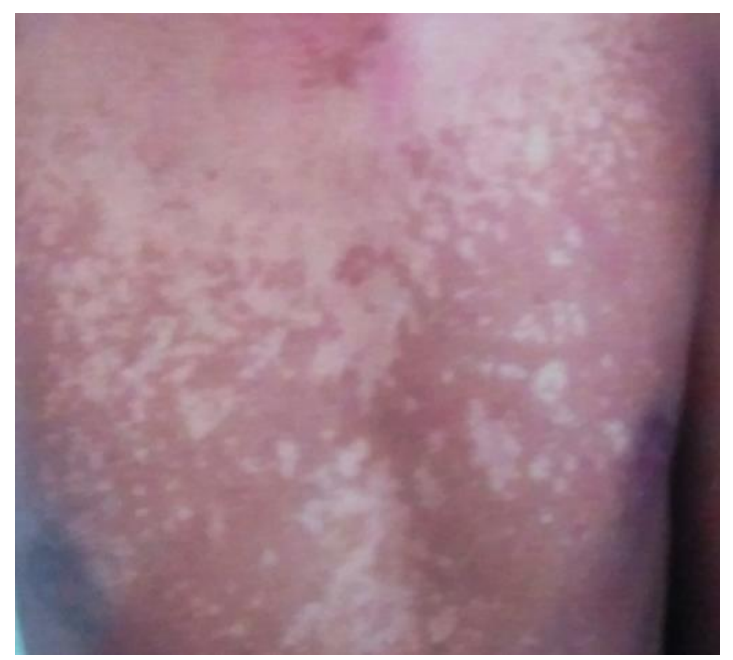

Fig. 5: Pityriasis versicolor

\section{Discussion}

Superficial mycosis is one of the most common skin diseases which brings patient to DVL outpatient department even after development in the field of medical science still this is considered as one of the major health problem. In our study we have found that most of the patients belongs to age group 15-45yrs that is $57.25 \%$ which is similar to the finding of various author, Abida Mallik et al found the most common age 15 to 40yrs, Parul Patel et al found that the most common age group was above $20 \mathrm{yrs}$ age, out study was also correlate as with the study of Sarma et al ${ }^{10-12}$

In present study we have observed that $78.83 \%$ of the patients were male which corroborates with the finding of Nidhi Negi et al. ${ }^{13}$ In our study we have found that the superficial mycosis was common in middle socioeconomic group. Which is not supported the work of Nidhi Negi et $\mathrm{al}^{13}$ but it corroborates with the finding of S Ranganatham et al. ${ }^{14}$

In present study most common clinical type isolated was Dermatophytosis that is $65.5 \%$ followed by candidiasis which is $18.66 \%$. This finding is supported by the work of wg c Dr Sanjiv Grover et al. ${ }^{9}$ But the study of Mishra $\mathrm{M}$ et al ${ }^{15}$ does not support our finding as per his study $\mathrm{T}$. Versicolor was the most common organism but study of Huda MM et al of upper Assam corroborates with our study.

In present study the most common dermatophytes were Tinea Cruris (49.10\%) followed by Tinea corporis $(30.53 \%)$ and Tinea Faciei was the least common isolates But there is variation in the finding of various authors.

\begin{tabular}{|l|c|}
\hline \multicolumn{1}{|c|}{ Author } & \multicolumn{1}{c|}{$\begin{array}{c}\text { Most common } \\
\text { dermatophytes }\end{array}$} \\
\hline $\begin{array}{l}\text { M Mishra et al } \\
\text { Raja and } \text { Menon }^{14} \text { et al }\end{array}$ & $\begin{array}{c}\text { Tinea Corporis } \\
\text { Tinea Cruris } \\
\text { Wg Dr. Sanjiv Grover }\end{array}$ \\
et al. & Tinea Tonsurans. \\
\hline
\end{tabular}

Tinea unguium was found in $13.23 \%$ of the patients, which almost similar to the work of Monika et al ${ }^{17}$ but Sumit Kumar et $\mathrm{al}^{18}$ found it $9.9 \%$, Tinea Pedis, Tinea Capitis, Tinea Barbie and Tinea Mannum incidence are below 5\% which similar the work of Monika et al and Sumit et al. ${ }^{17,18}$

In present study most common candidiasis type was balanoposthitis followed by vulvovaginitis which is supported by the work of P. Mnge et al. ${ }^{19}$

In present study we have higher culture positivity in comparison to $\mathrm{KOH}$ mount in dermatophytes and candidiasis that (62.84\% vs $42.74 \%)$ and (82\% vs $18 \%)$ then $P$. Versicolor, which is supported by the work of Abide mallik et al ${ }^{10}$ But the study of sunder Khadka et $\mathrm{al}^{20}$ does not Supports our study that is $\mathrm{KOH}$ positive was $44.5 \%$ and culture positivity was $55.5 \%$.

In present study the most common dermatophytes were Trichophyton species $(97.98 \%)$, out of that Trichophyton rubrum was the most common species followed by Trichophyton Mentagrophyte, this finding is supported by the study of Huda MM et al. ${ }^{16}$

But the study of sunder Khadka does not support our study as per his finding Trichophyton Mentagrophyte was the most common type. ${ }^{20}$ 
We have found $47.32 \%$ positivity in $\mathrm{KOH}$ mount and $82.14 \%$ positivity in culture in pityriasis versicolor. This finding is supported by the work of P Kannan et al. $^{21}$

We are able to isolate $12.62 \%$ non dermatophyte mould also in that most common species was Aspergillus Niger that is $48.97 \%$ of the isolates, rest were Aspergillus Flavus, Cladophialophora. Carrionii, Exophilia. Jeanselmei and Hortaea Werneekii.

But Wg C Dr. Sanjiv Grover ${ }^{9}$ et al finding does not support our finding as, the isolates in his study was $34 \%$ in that most common isolate was cladosporium spp. S. Khadka et al of Nepal also found NDM (non dermatophytes) in his study that was $27.9 \%{ }^{20} \mathrm{But}$ in the study of Aruna Vyas et al percentage of NDM was $6.7 \%$ which is less than our finding. ${ }^{22}$

\section{Conclusion}

To conclude our study has revealed a variation in clinical pattern of superficial mycosis and a spectrum of species causing superficial infection in our region. We have found that it is common in $2^{\text {nd }}$ and $3^{\text {rd }}$ decade of life with male predominance. It is common in middle income group. Dermatophytosis is most common clinical types and in that tinea cruris is most common clinical presentation, followed by candidiasis trichophyton rubrum was the most common species isolated. Among candidiasis balanoposthitis was most common presentation. We were able to isolate non dermatophytes mould also, in that aspergillus niger was most common species. So fungal injection are still one of the common skin infection require close attention.

\section{References}

1. Banaji N. Ananthanarayan and Paniker's Textbook of Microbiology India universities press $2009,8^{\text {th }}$ edition,. chapter 65-601, 602 P.

2. Aggarwal A, Arora U, Khanna S. Clinical and Mycological Study of Superficial Mycoses in Amritsar. Indian J Dermatol. 2002;47:4:218-20.

3. Cutaneous infections dermatophytosis, onychomycosis, and tinea versicolor. Infect Dis Clin North Am. 2003;17(1):87-112.

4. Ajello L Geographic distribution and prevalence of the Dermatophytes. Ann N Y Acad Sci. 1960 Aug 27;89:30-8.

5. Parul Patel, Summaiya Mulla, Disha Patel, Gauri Shankar Shrimali. (2010) A Study of superficial mycosis in south Gujarat region. National Journal of Community Medicine. 2010;1:85-88.

6. Grover WC, Roy CP. Clinico-mycological profile of superficial mycosis in a hospital in North-East India. Med J Armed Forces India. 2003;59:114-6.

7. Bindu V (2002) Clinico Mycological study of dermatophytosis in Calicut. IJDVL. 68:259-261.

8. WHO, 2005. Epidemiology and management of common skin diseases in children in developing countries. World Health Organization, Geneva. WHO/FCH/CAH/05.12.

9. WgC Dr Sanjiv Grove, Lt Col P Roy (2003) Clinicomycological Profile of Superficial mycosis in a Hospital in North East India, MJAFI. 59:114-119.

10. Abida Malik, Nazish Fatima and Parvez Anwar Khan, A Clinico-Mycological Study of Superficial Mycoses from a Tertiary Care Hospital of a North Indian Town Virology \& Mycology. Volume $3 \cdot$ Issue 3 135.

11. Parul Patel, Summaiya Mulla, Disha Patel, Gaurishankar. A Study of Superficial Mycosis in South Gujarat REGION. National Journal of Community Medicine. 2010, Vol. 1, Issue 2.

12. Sarma S. Borthakur AK. A Clinico-Epidermatological Study of Dermatophytoses in Northest India. Indian J of Dermatol Venereol Leprol. 2007;73:6:427-8.

13. Nidhi Negi, Vibha Tripathi, Reshmi Chanda Choudhury, Jitendra Singh Bist, Neeti Kumari and Iva Chandola Clinicomycological Profile of Superficial Fungal Infections Caused by Dermatophytes in a Tertiary Care Centre of North India. Int J Curr Microbiol App Sci 2017;6(8):3220-3227.

14. S Ranganathan, Thangam Menon, G Selvi Sentamil, Effect of socio-economic status on the prevalence of dermatophytosis in Madras. Indian journal of dermatology, venereology and leprology. 1995;61(1):1618.

15. M Mishra, S Mishra, PC Singh, BC Mishra, Clinicomycological profile of superficial mycoses. Indian journal of dermatology, venereology and leprology. 1998;64(6):283-285.

16. Huda $\mathrm{MM}^{1}$, Chakraborty N, Sharma Bordoloi JN. A clinico-mycological study of superficial mycoses in upper Assam. Indian J Dermatol Venereol Leprol. 1995;61(6):329-32.

17. Monika, Sunil Kumar Gupta, Deepinder K. Chhina Clinico-Mycological correlation of Superficial Fungal Infections. The Gulf Journal of Dermatology and Venereology. 2016;23(1).

18. Sumit Kumar P Shrikara Mallya Pallavi Kumari ClinicoMycological Study of Dermatophytosis in a Tertiary Care Hospital, 27, International Journal of Scientific Study. March 2014 | Vol 1 | Issue 6.

19. P. Mnge, B.I. Okeleye, S.D. Vasaikar, and T. Apalata. Species distribution and antifungal susceptibility patterns of Candida isolates from a public tertiary teaching hospital in the Eastern Cape Province. South Africa, Braz J Med Biol Res. 2017;50(6):e5797.

20. Sundar Khadka, Jeevan Bahadur Sherchand, Dinesh Binod Pokharel, Bharat Mani Pokhrel, Shyam Kumar Mishra, Subhash Dhital,2 and Basista Rijal, Clinicomycological Characterization of Superficial Mycoses from a Tertiary Care Hospital in Nepal, Dermatology Research and Practice, Volume 2016, Article ID 9509705, 7 pages.

21. P Kannan, *C Janaki, GS Selvi. Prevalence of dermatophytes and other fungal agents isolated from clinicalsamples. Indian Journal of Medical Microbiology, 2006;24(3):212-5.

22. Vyas A, Pathan N, Sharma R, Vyas L. A clinicomycological study of cutaneous mycoses in Sawai Man Singh Hospital of Jaipur, North India. Ann Med Health Sci Res. 2013;3:593-7.

How to cite this article: Ramesh $\mathrm{K}$, Murthy MSN, Annapurna MM. Prospective clinico mycological study of superficial mycosis in coastal Andhra Pradesh. Ind J Clin Exp Dermatol. 2018;4(3): 165-169. 